\title{
Simulation-based optimization of control policy on multi-echelon inventory system for fresh agricultural products
}

\author{
Guangyin $\mathrm{Xu}^{1,2}$, Jihao Feng ${ }^{1,2}$, Fenglei Chen ${ }^{3}$, Heng Wang ${ }^{1,2}$, Zhenfeng Wang ${ }^{1,2^{*}}$ \\ (1. College of Mechanical and Electrical Engineering, Henan Agricultural University, Zhengzhou 450002, China; \\ 2. Collaborative Innovation Center of Biomass Energy, Henan Province. Zhengzhou 450002, China; \\ 3. Guizhou Province Branch of China National Tobacco Company, Guiyang 550000, China)
}

\begin{abstract}
As fresh agricultural products are perishable and vulnerable, reducing inventory cost is a strategic target for supply chain enterprises. How to design a reliable multi-echelon inventory control policy is still a great challenge. Therefore, the inventory cost of a three-level fresh agricultural products inventory system was firstly mathematically analyzed. Then, the simulation-based optimization model of the multi-echelon inventory system for fresh agricultural products was proposed by using the Flexsim simulation software and the improved particle swarm optimization algorithm. Finally, the multi-echelon inventory system is simulated based on a large number of survey data. Simulation results demonstrate that the proposed simulation-based optimization model of multi-echelon inventory system for fresh agricultural products can provide decision-making and technical support for the formulation of inventory control policy, and also it shows that the modeling of system simulation is an effective method to solve the problem of complex system.
\end{abstract}

Keywords: multi-echelon inventory system, simulation-based optimization, fresh agricultural products, control policy, Flexsim simulation software

DOI: $10.25165 /$ j.ijabe. 20191202.2834

Citation: Xu G Y, Feng J H, Chen F L, Wang H, Wang Z F. Simulation-based optimization of control policy on multi-echelon inventory system for fresh agricultural products. Int J Agric \& Biol Eng, 2019; 12(2): 184-194.

\section{Introduction}

Fresh agricultural products are the necessities in our daily life. As fresh agricultural products are perishable and vulnerable, it is difficult for enterprises to arrange the order, inventory and shipment. In real life, the custom demand for fresh agricultural products is dynamic and random, thus, the formulation of multi-echelon inventory control policy for fresh agricultural products in the supply chain environment are more complicated and difficult. Therefore, one of the most challenging topics is how to design a reliable multi-echelon inventory control policy, which is also the prime condition for practical deployments.

Various multi-echelon inventory control policy have been studied in literatures. Most of them considered various factors in the inventory system, and then established the mathematical analysis model to solve the problem ${ }^{[1-6]}$. However, the inventory problem under supply chain environment is stochastic and dynamic, and the mathematical model has great limitations in solving this kind of problem ${ }^{[7,8]}$. With the simulation-based optimization approach proposed ${ }^{[9-12]}$, many scholars used simulation-based optimization approach to study it. Köchel and Nieländer ${ }^{[7]}$ show

Received date: 2017-09-07 Accepted date: 2019-02-26

Biographies: Guangyin $\mathrm{Xu}, \mathrm{PhD}$, Professor, research interests: agricultural products logistics technology and system engineering. Email: xgy4175@ 126.com; Jihao Feng, MS, research interests: agricultural products logistics technology and system engineering. Email: ifengjh@foxmail.com; Fenglei Chen, Senior Agronomist, research interests: agricultural products logistics technology. Email: cfl-fengli@163.com; Heng Wang, PhD, Lecturer, research interests: agricultural products logistics technology. Email: dawn_wangh@163.com.

*Corresponding author: Zhenfeng Wang, $\mathrm{PhD}$, Associate Professor, research interests: agricultural products logistics technology and system engineering. Henan Agricultural University, No.63, Agricultural Road, Zhengzhou 450002, China. Tel: +86-371-63558040, Email: zhenfengking@qq.com. that simulation optimisation successfully can be applied to define optimal policies in very general multi-echelon inventory systems through a numerical example. Starting from multi-period newsvendor problem, Heidary and Aghaie et al. ${ }^{[13]}$ establishes a simulation model for customer demand behavior, and solves a bi-objective optimization problem with uncertain customer demand and supply interruption by using simulation-based optimization method. Case study shows that risk-sensitive retailers tend to show more risk aversion behavior and relative to service level the profit is more important. Using the idea of control engineering, Zhao and Wang ${ }^{[14]}$ applies feedback control method to a three-level inventory system. Proportional integral algorithm is used to modify the model control strategy of three-level inventory system, and its simulation model is established. By using simulation-based optimization method, Avci and Selim ${ }^{[15]}$ studies the shelf premium problem in a multi-objective and intensive supply chain. Differential evolution algorithm is used to determine the parameters of demand forecasting adjustment factor and safe inventory to optimize the objective of system optimization. Compared with the results of non-dominated sequencing genetic algorithm, it shows that the proposed method can effectively solve the optimal replenishment problem in supply chain environment. Güller et al. ${ }^{[16]}$ studied a multi-echelon production-inventory system under a stochastic environment and used simulation-based optimization approach to determine the optimal inventory control parameters. He et al. ${ }^{[17]}$ proposed a novel simulation-based heuristic method to solving the modeling and optimization problem of multi-echelon contain in supply chain network, where the objective is subject to the minimization of the total supply chain service cost. Thammatadatrakul and Chiadamrong ${ }^{[18]}$ studies the problem of remanufactured inventory with different priorities. A simulation-based optimization method combining mixed integer programming and simulation model is proposed. Saif A and 
Elhedhli ${ }^{[19]}$ used a novel hybrid simulation-optimization approach to solve cold supply chain design problem which modeled as a mixed-integer concave minimization problem with dual objectives of minimizing the total cost- including capacity, transportation, and inventory costs - and the global warming impact. Attar et al. ${ }^{[20]}$ used a hybrid simulation-optimization approach to optimize a continuous-review, base-stock inventory model with general compound demands, random lead times, and lost sales which the customers' inter-arrival times, demand sizes, and lead times are extended in a probabilistic situation with free distributions.

Motivated by above literatures, to use simulation and optimization in multi-echelon inventory control policy is accepted as a promising way. Note that base on the sufficient consideration of the perishable properties of fresh agricultural products, multi-echelon inventory control policy for fresh agricultural products is proposed. Therefore, the inventory cost of a three-level fresh agricultural products inventory system is firstly mathematical analyzed. Then, the simulation-based optimization model of the multi-echelon inventory system for fresh agricultural products is established based on the Flexsim simulation software and the improved particle swarm optimization algorithm. Finally, in order to verify that the simulation-based optimization method has more advantages to solve complex system problems than mathematical method, the multi-echelon inventory system is simulated based on a large number of survey data.

\section{Problem description and model analysis}

\subsection{System description}

Multilevel inventory problem consists of the sub-problem of upstream manufacturing system and the sub-problem of downstream distribution system. In the manufacturing system, manufacturer enterprises have clear production plan, and thus inventory demand is mostly a deterministic problem. However, in the distribution system, the market-oriented inventory demand problem is mostly stochastic. In this paper, a three-level fresh agricultural products inventory system, which consists of one manufacturer, multiple distributors, multiple retailers, and one supplier, is considered, as shown in Figure 1. Every node in the system uses (r, Q) inventory control policy ( $r$-the reorder point, Q-replenishment quantity). The ( $r, \mathrm{Q})$ inventory control policy is a fixed order strategy: when storage (balance) is $I$, if $I>r$, storage is not added; if $I \leq r$, storage is supplemented.

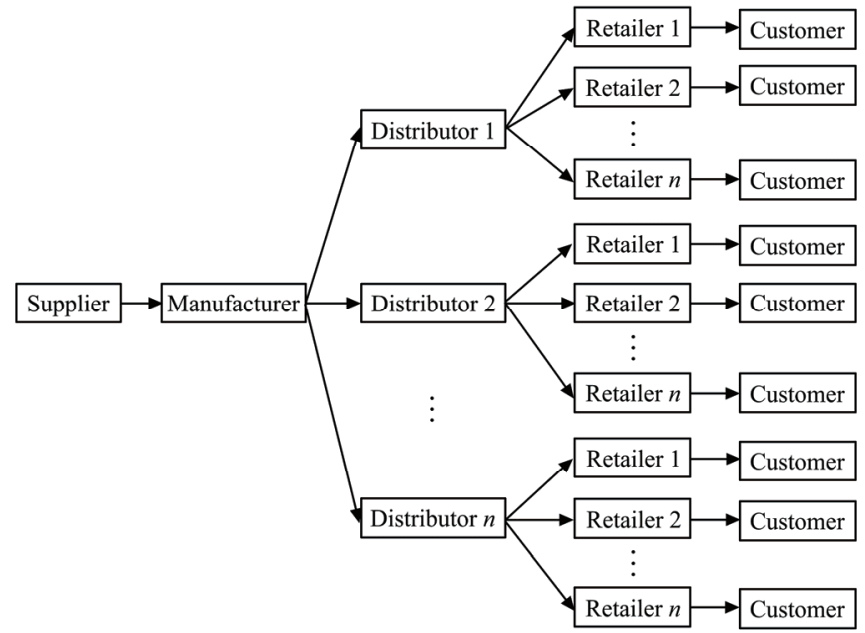

Figure 1 Multi-echelon inventory system of fresh agricultural products
In the system, the demand information flows from the customer side to the supply side, and the logistics flows from the supplier side to the customer side. The arrival time and demand of customers are stochastic. When the retailers are out of stock, the customers will no longer wait, resulting in the shortage loss. When the distributors (manufacturers) are out of stock, the retailers (distributors) will wait for the demand to be met. Replenishment of the suppliers is according to the manufacturer's demand information. In this paper, we mainly consider the three-level inventory control strategy problem of manufacturers, distributors and retailers, so it is assumed that the supplier has unlimited supply capacity so that it will never be out of stock. Except the part from retailers to customers, the replenishment of each node in the system has delayed.

\subsection{Inventory cost}

The major costs in the system include order cost, storage cost, shortage cost, transportation cost and goods loss cost.

1) Storage cost

The storage costs including funds interest, insurance and the use of storage are directly proportional to the amount and time of storage.

\section{2) Order cost}

The order cost is the cost caused by replenishing the inventory in a single time, which is related to the number of orders, and not related to the quantity of the orders.

3) Shortage cost

The shortage cost is the loss caused by that the storage cannot meet the demand, such as the loss of lost sales opportunities, additional expenditures for delayed delivery, etc. In this paper, the shortage cost is considered in the different service levels. In general, the greater the quantity of shortage is, the greater the loss is and the lower the service level is.

4) Transportation cost

In this paper, the transportation cost of the unit goods is considered, which is related to the orders quantity and the number of orders.

\section{5) Goods loss cost}

Goods loss costs mainly include the physical loss and deterioration loss during transportation and sale. Manufacturers and distributors are mainly related to the loss of transportation. Retailers, in addition to transportation loss, are mainly related to the number of days in stock: longer stock results in more rotten goods.

\subsection{Mathematical model of multi-echelon inventory system of fresh agricultural products}

In order to verify and compare the simulation model, the perishable inventory system mathematical model is established. Assumptions of the model:

1) The customer demand and customer arrival time interval are the mathematical expectation of exponentially distribution, the damage rate and delay time are the mathematical expectation of uniform distribution.

2) In the model, lead time is the expected value of the random variable, it's a constant value. So it does not considered backorder in this model. When the inventory is zero, it simply place the order point ahead of a lead time value.

Variables which are used in the model are provided as follows:

\begin{tabular}{|clrl|}
\hline$r^{p} \quad$ order point of manufacturer & $r_{i}^{d}$ & $\begin{array}{l}\text { order point of } i^{\text {th }} \text { distributor } \\
r_{i}^{r}\end{array}$ order point of $i^{\text {th }}$ retailer & $I(t)_{i}^{r} \begin{array}{l}\text { inventory level of the } i^{\text {th }} \\
\text { retailer at time } t\end{array}$
\end{tabular}




\begin{tabular}{|c|c|c|c|}
\hline$\alpha_{r}$ & $\begin{array}{l}\text { mathematical expectation of } \\
\text { retailer's deterioration rate }\end{array}$ & $\alpha_{d}$ & $\begin{array}{l}\text { mathematical expectation of } \\
\text { distributor's deterioration rate }\end{array}$ \\
\hline$\alpha_{p}$ & $\begin{array}{l}\text { mathematical expectation of } \\
\text { manufacturer's deterioration rate }\end{array}$ & $D_{i}^{r}$ & $\begin{array}{l}\text { mathematical expectation of } \\
\text { retailers' demand }\end{array}$ \\
\hline$D_{i}^{d}$ & $\begin{array}{l}\text { mathematical expectation of } \\
\text { distributors' demand }\end{array}$ & $D^{p}$ & $\begin{array}{l}\text { mathematical expectation of } \\
\text { manufacturer's demand }\end{array}$ \\
\hline$Q_{i}^{r}$ & order quantity of $i^{\text {th }}$ retailer & $Q_{i}^{d}$ & order quantity of $i^{\text {th }}$ distributor \\
\hline$Q^{P}$ & $\begin{array}{l}\text { order quantity of } i^{\text {th }} \text { distributor } \\
\text { manufacturer }\end{array}$ & $S_{i}^{r}$ & storage costs of $i^{\text {th }}$ retailer \\
\hline$S_{i}^{d}$ & storage costs of $i^{\text {th }}$ distributor & $S^{p}$ & storage costs of manufacturer \\
\hline$L_{i}^{r}$ & goods loss cost of $i^{\text {th }}$ retailer & $L_{i}^{d}$ & $\begin{array}{l}\text { goods loss cost of } i^{\text {th }} \\
\text { distributor }\end{array}$ \\
\hline$L^{P}$ & goods loss cost of manufacturer & $O_{i}^{r}$ & ordering costs of $i^{\text {th }}$ retailers \\
\hline$O_{i}^{d}$ & ordering costs of $i^{\text {th }}$ distributors & $O^{P}$ & $\begin{array}{l}\text { ordering costs of } \\
\text { manufacturer }\end{array}$ \\
\hline$C_{i}^{r}$ & $\begin{array}{l}\text { transportation costs of } i^{\text {th }} \\
\text { retailers }\end{array}$ & $C_{i}^{d}$ & $\begin{array}{l}\text { transportation costs of } i^{\text {th }} \\
\text { distributors }\end{array}$ \\
\hline$C^{p}$ & $\begin{array}{l}\text { transportation costs of } \\
\text { manufacturer }\end{array}$ & $C I R_{i}$ & $\begin{array}{l}\text { average inventory cost of } i^{\text {th }} \\
\text { retailer in single cycle }\end{array}$ \\
\hline$C L R_{i}$ & $\begin{array}{l}\text { average goods loss cost of } \underline{i}^{\text {th }} \\
\text { retailer in single cycle }\end{array}$ & $C O R_{i}$ & $\begin{array}{l}\text { average ordering cost of } i^{\text {th }} \\
\text { retailer in single cycle }\end{array}$ \\
\hline$C T R_{i}$ & $\begin{array}{l}\text { average transportation cost of } i^{\text {th }} \\
\text { retailer in single cycle }\end{array}$ & $T R C_{\min }$ & $\begin{array}{l}\text { minimum total cost of retailer } \\
\text { during the inspection period }\end{array}$ \\
\hline$C I D_{i}$ & $\begin{array}{l}\text { average inventory cost of } i^{\text {th }} \\
\text { distributor in single cycle }\end{array}$ & $C L D_{i}$ & $\begin{array}{l}\text { average goods loss cost of } i^{\text {th }} \\
\text { distributor in single cycle }\end{array}$ \\
\hline$C O D_{i}$ & $\begin{array}{l}\text { average ordering cost of } i^{\text {th }} \\
\text { distributor in single cycle }\end{array}$ & $C T D_{i}$ & $\begin{array}{l}\text { average transportation cost of } \\
i \text { th distributor in single cycle }\end{array}$ \\
\hline$T D C_{\min }$ & $\begin{array}{l}\text { minimum total cost of distributor } \\
\text { during the inspection period }\end{array}$ & $C I P$ & $\begin{array}{l}\text { average inventory cost of } \\
\text { manufacturer in single cycle }\end{array}$ \\
\hline$C L P$ & $\begin{array}{l}\text { average goods loss cost of } \\
\text { manufacturer in single cycle }\end{array}$ & $C O P$ & $\begin{array}{l}\text { average ordering cost of } \\
\text { manufacturer in single cycle }\end{array}$ \\
\hline$C T P$ & $\begin{array}{l}\text { average transportation cost of } \\
\text { manufacturer in single cycle }\end{array}$ & $T P C_{\min }$ & $\begin{array}{l}\text { minimum total cost of } \\
\text { manufacturer }\end{array}$ \\
\hline$T T C_{\min }$ & $\begin{array}{l}\text { minimum total cost of the } \\
\text { inventory system }\end{array}$ & & \\
\hline
\end{tabular}

According to the basic inventory model for perishable goods (Equation (1)), establishment of a perishable inventory mode ${ }^{[1]}$. The level of inventory changes is shown in Figure 2.

$$
\frac{d I(t)}{d t}=-\alpha I(t)-D
$$

where, $I(t)$ is inventory level at time $t ; \alpha$ is mathematical expectation of deterioration rate and $D$ is customer demand.

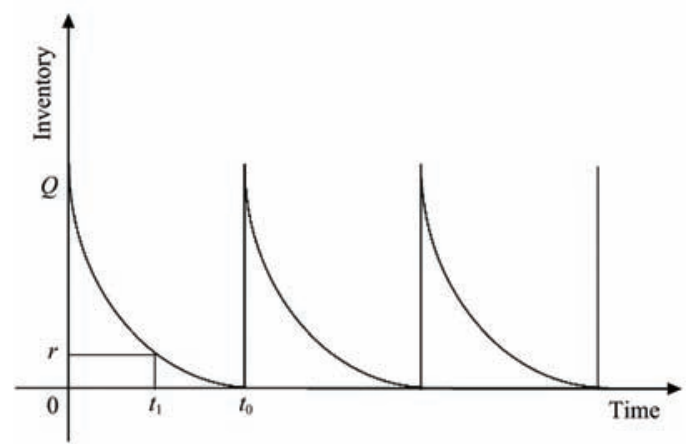

Figure 2 The change of inventory level

\subsubsection{Inventory model of retailer}

According to Equation (1) and the boundary conditions $I(0)_{i}^{r}=Q_{i}^{r}$. The solution of differential equation is:

$$
I(t)_{i}^{r}=\left(\frac{D_{i}^{r}}{\alpha_{r}}+Q_{i}^{r}\right) e^{-\alpha_{r} t}-\frac{D_{i}^{r}}{\alpha_{r}}
$$

So the average inventory cost in single cycle is:

$$
\begin{aligned}
C I R_{i} & =\frac{1}{t_{0}} S_{i}^{r} \int_{0}^{t_{0}} I(t)_{i}^{r} d t \\
& =\frac{\left[\left(D_{i}^{r}+Q_{i}^{r} \alpha_{r}\right)\left(1-e^{-\alpha_{r} t_{0}}\right)-D_{i}^{r} t_{0} \alpha_{r}\right] S_{i}^{r}}{t_{0} \alpha_{r}{ }^{2}}
\end{aligned}
$$

Average goods loss cost in single cycle is:

$$
\begin{aligned}
C L R_{i} & =\frac{1}{t_{0}} L_{i}^{r} \int_{0}^{t_{0}} \alpha_{r} I(t)_{i}^{r} d t \\
& =\frac{\left[\left(D_{i}^{r}+Q_{i}^{r} \alpha_{r}\right)\left(1-e^{-\alpha_{r} t_{0}}\right)-D_{i}^{r} t_{0} \alpha_{r}\right] L_{i}^{r} \alpha_{r}}{t_{0} \alpha_{r}{ }^{2}}
\end{aligned}
$$

Average ordering cost in single cycle is:

$$
\operatorname{COR}_{i}=\frac{O_{i}^{r}}{t_{0}}
$$

Average transportation cost in single cycle is:

$$
C T R_{i}=\frac{C_{i}^{r} Q_{i}^{r}}{t_{0}}
$$

According to $I\left(t_{0}\right)=0, t_{0}$ can be calculated

$$
\begin{gathered}
I\left(t_{0}\right)_{i}^{r}=\left(\frac{D_{i}^{r}}{\alpha_{r}}+Q_{i}^{r}\right) e^{-\alpha_{r} t_{0}}-\frac{D_{i}^{r}}{\alpha_{r}}=0 \\
t_{0}=-\frac{\ln \frac{D_{i}^{r}}{D_{i}^{r}+D_{i}^{r} \alpha_{r}}}{\alpha_{r}}
\end{gathered}
$$

During the investigation period, the total inventory cost objective function is:

$$
\begin{aligned}
& T R C_{\text {min }}=\sum_{i=1}^{n} T_{t}\left(C I R_{i}+C L R_{i}+C O R_{i}+C T R_{i}\right) \\
& =\sum_{i=1}^{n} T_{t}\left[\frac{\left(S_{i}^{r}+L_{i}^{r} \alpha_{r}+C_{i}^{r} \alpha_{r}\right) Q_{r i}+O_{i}^{r} \alpha_{r}}{\ln \frac{D_{i}^{r}+Q_{i}^{r} \alpha_{r}}{D_{i}^{r}}}-\frac{D_{i}^{r}\left(S_{i}^{r}+L_{i}^{r} \alpha_{r}\right)}{\alpha_{r}}\right]
\end{aligned}
$$

According to Equation (9), $r_{i}^{r}$ can be obtained after the order quantity of $Q_{i}^{r}$. By formula

$$
I\left(t_{1}\right)=\left(\frac{D_{i}^{r}}{\alpha_{r}}+Q_{i}^{r}\right) e^{-\alpha_{r} t_{1}}-\frac{D_{i}^{r}}{\alpha_{r}}=r_{i}^{r}
$$

and formula:

$r_{i}^{r}$ is obtained:

$$
t_{1}=t_{0}-t
$$

$$
r_{i}^{r}=\left(\frac{D_{i}^{r}}{\alpha_{r}}+Q_{i}^{r}\right) e^{\left(\ln \frac{D_{i}^{r}}{D_{i}^{r}+Q_{i}^{\prime} \alpha_{r}}+\alpha_{r} t\right)}-\frac{D_{i}^{r}}{\alpha_{r}}
$$

\subsubsection{Inventory model of distributor}

When the retailer's order quantity $Q_{i}^{r}$ is determined, the corresponding distributor's demand is $D_{i}^{d}=\sum_{i=1}^{n} Q_{i}^{r} / t_{0}$. As the same as the calculation process of the retailer, the objective function of the total cost of the distributor during the inspection period is:

$$
\begin{aligned}
T D C_{\min } & =\sum_{i=1}^{n} T_{t}\left(C I D_{i}+C L D_{i}+C O D_{i}+C T D_{i}\right) \\
& =\sum_{i=1}^{n} T_{t}\left[\frac{\left(S_{i}^{d}+L_{i}^{d} \alpha_{d}+C_{i}^{d} \alpha_{d}\right) Q_{i}^{d}+O_{i}^{d} \alpha_{d}}{\ln \frac{D_{i}^{d}+Q_{i}^{d} \alpha_{d}}{D_{i}^{d}}}-\frac{D_{i}^{d}\left(S_{i}^{d}+L_{i}^{d} \alpha_{d}\right)}{\alpha_{d}}\right]
\end{aligned}
$$


And the $r_{i}^{r}$ is:

$$
r_{i}^{d}=\left(\frac{D_{i}^{d}}{\alpha_{d}}+Q_{i}^{d}\right) e^{\left(\ln \frac{D_{i}^{d}}{D_{i}^{d}+Q_{i}^{d} \alpha_{d}}+\alpha_{d} t\right)}-\frac{D_{i}^{d}}{\alpha_{d}}
$$

\subsubsection{Inventory model of manufacturer}

When the retailer's order quantity $Q_{i}^{d}$ is determined, the corresponding manufacturer's demand is $D^{p}=\sum_{i=1}^{n} Q_{i}^{d} / t_{0}$, as the same as the calculation process of the retailer, the objective function of the total cost of the manufacturer during the inspection period is:

$$
\begin{aligned}
T P C_{\min } & =\sum_{i=1}^{n} T_{t}(C I P+C L P+C O D+C T D) \\
& =\sum_{i=1}^{n} T_{t}\left[\frac{\left(S^{p}+L^{P} \alpha_{r}+C^{p} \alpha_{p}\right) Q_{p}+O^{P} \alpha_{p}}{D^{p}+Q^{P} \alpha_{p}}\right. \\
D^{p} & \left.-\frac{D^{p}\left(S^{p}+L^{P} \alpha_{p}\right)}{\alpha_{p}}\right]
\end{aligned}
$$

And the $r^{p}$ is:

$$
\left.r^{p}=\left(\frac{D^{P}}{\alpha_{p}}+Q^{P}\right) e^{\left(\ln \frac{D^{P}}{D^{P}+Q^{P} \alpha_{p}}+\alpha_{p} t\right.}\right)-\frac{D^{P}}{\alpha_{p}}
$$

The total cost objective function of the inventory system is:

$$
T T C_{\min }=T R C_{\min }+T D C_{\min }+T P C_{\min }
$$

Model constraint conditions are:

$$
\text { s.t. }\left\{\begin{array}{l}
r^{p}<Q^{P} \\
r_{i}^{d}<Q_{i}^{d} \\
r_{i}^{r}<Q_{i}^{r}
\end{array}\right.
$$

\section{Simulation-based optimization approach}

The simulation approach can intuitively describe and reflect the characteristics of the complex logistics system with numerous factors. However, the simulation model cannot optimize the system. Therefore, we combine the simulation and optimization method together, and use the output of the simulation to guide the optimization algorithm to find the optimal value, so that the output response will constantly improve in the simulation environment, aiming to achieve the optimization of the system performance. Lots of scholars have studied on the simulation-based optimization approach $^{[9-12]}$. In addition to the inventory research, many scholars have used simulation-based optimization approach to solve a variety of practical problems ${ }^{[21-25]}$ in recent years. In this paper, the Flexsim software and improved particle swarm optimization algorithm are used to establish the simulation-based optimization model. The operation flow of simulation-based optimization approach is shown in Figure 3.

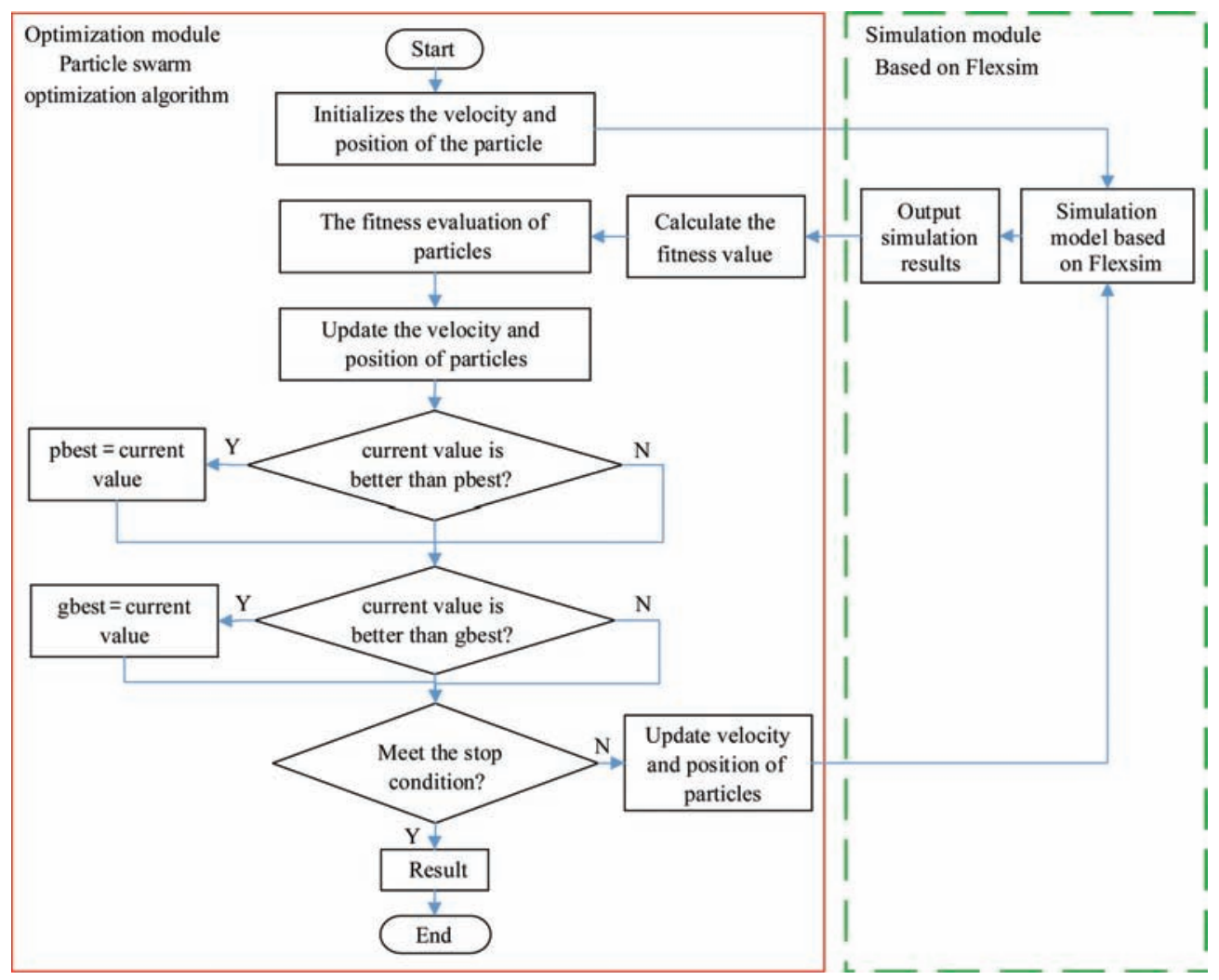

Figure 3 Operation flow of simulation-based optimization approach

Flexsim is a kind of general simulation software for discrete event system, with functions including simulation model design, fabrication and analysis. Using the object-oriented technology and with 3D display function, the modeling is convenient and fast. Many scholars have used Flexsim to solve a variety of practical problems ${ }^{[26-29]}$. The general steps of logistics simulation modeling based on Flexsim are divided into system investigation before modeling, model building, data input, and realization of simulation logic, model validation, and result output and simulation analysis ${ }^{[30]}$.

Particle swarm optimization algorithm is an effective optimization tool for nonlinear continuous optimization problems, combinatorial optimization problems and mixed integer nonlinear optimization problems ${ }^{[31]}$. It has the advantages of easy implementation and fast convergence speed, etc.

The velocity and position update equations of particles are shown in Equation (19) and Equation (20).

$$
\begin{gathered}
v_{i d}^{k+1}=w v_{i d}^{k}+z_{1} \varepsilon\left(p_{i d}^{k}-x_{i d}^{k}\right)+z_{2} \gamma\left(p_{g d}^{k}-x_{i d}^{k}\right) \\
x_{i d}^{k+1}=x_{i d}^{k}+v_{i d}^{k+1}
\end{gathered}
$$

where, $v_{i d}^{k}$-the velocity of the $i^{\text {th }}$ particle in $d^{\text {th }}$ dimension and the 
$k$ th iteration; $z_{1}, z_{2}$-learning factor; $\varepsilon, \gamma$-random number between $[0,1] ; x_{i d}^{k}$-the position of the $i^{\text {th }}$ particle in $d^{\text {th }}$ dimension and the $k$ th iteration; $p_{i d}^{k}$-the optimal value of the current particle; $p_{g d}^{k}$-global optimal value.

In the particle swarm optimization algorithm, the convergence speed of the algorithm can be adjusted by adjusting the inertia weight. The larger $w$ value can enhance the global search capability of the algorithm, while the smaller $w$ value can enhance the local search capability. Therefore, some scholars proposed the linearly decreasing weight method, and got better results through validation $^{[32]}$. This kind of weight descending policy is an exponential curve. In the iterative process, the weight value updates according to the Equation (21).

$$
\left.w=w_{\text {end }}\left(w_{\text {start }} / w_{\text {end }}\right)^{1 /\left(1+z_{3} t / t_{\max }\right.}\right)
$$

where, $w$ is the weight value; $z_{3}$ is the an adjustment parameter of $w$; $t_{\max }$ is the maximum number of iterations; $t$ is the current iteration number; $w_{\text {start }}$ is the initial inertia weight; $w_{\text {end }}$ is the inertia weight of the maximum allowable number of iterations.

The speed compression factor can effectively make the particle swarm convergence and search the global and partially to obtain a better optimal value ${ }^{[33]}$. The expression of velocity compression factor and the update equation of velocity are shown as follows

$$
\begin{gathered}
\varphi=2 /\left|2-\left(z_{1}+z_{2}\right)-\left(\left(z_{1}+z_{2}\right)^{2}-4^{*}\left(z_{1}+z_{2}\right)\right)^{\frac{1}{2}}\right| \\
v_{i d}^{k+1}=\varphi\left(w v_{i d}^{k}+z_{1} \varepsilon\left(p_{i d}^{k}-x_{i d}^{k}\right)+z_{2} \gamma\left(p_{g d}^{k}-x_{i d}^{k}\right)\right)
\end{gathered}
$$

where, $\varphi$ is the compression factor, $z_{1}+z_{2} \geq 4$.

\section{Simulation case and result analysis}

\subsection{Case description}

Consider a multi-echelon inventory problem of fresh agricultural products in a certain chain enterprise. In certain area, this enterprise has a multi-echelon inventory system of fresh agricultural products, which consists of one manufacturer, two distributors and five retailers. Distributor 1 supplies goods to Retailer 1 and Retailer 2, Distributor 2 supplies goods to Retailer 3, Retailer 4 and Retailer 5, the relevant parameters of the inventory system are shown in Table 1 . The shortage costs under different service levels $f$ are shown in Table 2. The retailers should also consider the number of storage days, the loss rates are shown in Table 3. It shows the change of loss rate with the storage days increase, if the goods are placed more than three days, they will lose their selling value, resulting in the totally loss. All the data

\begin{tabular}{|c|c|c|c|c|c|c|c|c|c|}
\hline System nodes & $\begin{array}{c}\mathrm{SC} / \\
\text { Yuan } \cdot \mathrm{kg}^{-1} \cdot \mathrm{d}^{-1}\end{array}$ & $\begin{array}{c}\mathrm{OC} / \\
\text { Yuan per time }\end{array}$ & $\begin{array}{c}\mathrm{TC} / \\
\text { Yuan } \mathrm{kg}^{-1}\end{array}$ & Loss rate & $\begin{array}{c}\text { Initial } \\
\text { inventory } / \mathrm{kg}\end{array}$ & $\begin{array}{c}\text { Delay time/ } \\
\mathrm{d}\end{array}$ & $\begin{array}{l}\text { Demand/ } \\
\mathrm{kg}\end{array}$ & $\begin{array}{l}\text { Demand time } \\
\text { interval/d }\end{array}$ & $\mathrm{GLC} / \mathrm{kg}$ \\
\hline Manufacturer & 0.02 & 40 & 0.06 & $\mathrm{U}(0.05,0.08)$ & 3000 & $\mathrm{U}(0.7,1)$ & - & - & 0.2 \\
\hline Distributor 2 & 0.024 & 35 & 0.08 & $\mathrm{U}(0.01,0.04)$ & 1100 & $\mathrm{U}(0.5,0.8)$ & - & - & 0.3 \\
\hline Retailer1 & 0.03 & 20 & 0.1 & - & 250 & $\mathrm{U}(0.4,0.7)$ & $\mathrm{E}(7)$ & $\mathrm{E}(0.03)$ & 0.5 \\
\hline Retailer 2 & 0.03 & 20 & 0.1 & - & 250 & $\mathrm{U}(0.4,0.7)$ & $\mathrm{E}(7)$ & $\mathrm{E}(0.03)$ & 0.5 \\
\hline Retailer 3 & 0.03 & 20 & 0.1 & - & 250 & $\mathrm{U}(0.4,0.7)$ & $\mathrm{E}(5)$ & $\mathrm{E}(0.03)$ & 0.5 \\
\hline Retailer 4 & 0.03 & 20 & 0.1 & - & 250 & $\mathrm{U}(0.4,0.7)$ & $E(6)$ & $\mathrm{E}(0.03)$ & 0.5 \\
\hline Retailer 5 & 0.03 & 20 & 0.1 & - & 250 & $\mathrm{U}(0.4,0.7)$ & $\mathrm{E}(5)$ & $\mathrm{E}(0.03)$ & 0.5 \\
\hline
\end{tabular}
were obtained through market research.

Table 1 The relevant parameters of the inventory system

Note: $\mathrm{SC}=$ Storage cost, $\mathrm{OC}=$ Order cost, $\mathrm{TC}=$ Transportation cost, $\mathrm{GLC}=$ Goods loss cost.

Table 2 Shortage cost under different service level $f$

\begin{tabular}{cccccccc}
\hline Range of $f$ & $95 \leq f<100$ & $90 \leq f<95$ & $85 \leq f<90$ & $80 \leq f<85$ & $75 \leq f<80$ & $f<70$ \\
\hline Cost & 0.02 & 0.05 & 0.1 & 0.2 & 0.5 & 0.8 \\
\hline
\end{tabular}

Table 3 Loss rate of retailer under different storage days

\begin{tabular}{cccc}
\hline Storage time/d & 1 & 2 & 3 \\
\hline Loss rate & $\mathrm{U}(0.04,0.06)$ & $\mathrm{U}(0.08,0.1)$ & $\mathrm{U}(0.2,0.3)$ \\
\hline
\end{tabular}

4.2 The establishment of simulation-based optimization model

4.2.1 Layout of simulation model

In the Flexsim environment, we use the "Queue" as the warehouse of each node in the system to store the "Item" which represents for goods. Taking five "Sources" as customers and generating random demand for five retailers; Taking one "Source" as a supplier to generate "Item" which represents for goods; Each warehouse node in the system has two "Source" to generate initial inventory and replenishment needs; The "Sink" is used to dispose the orders whose demands are filled up. Using "Sink" to absorb "Item" to simulate the customers receive the goods from retailers. In the simulation model, the global table is used to record the order quantity of each node, the quantity of inventory, shortage and goods loss as well as the order point and order quantity at all levels. The layout of the simulation model is shown in Figure 4.

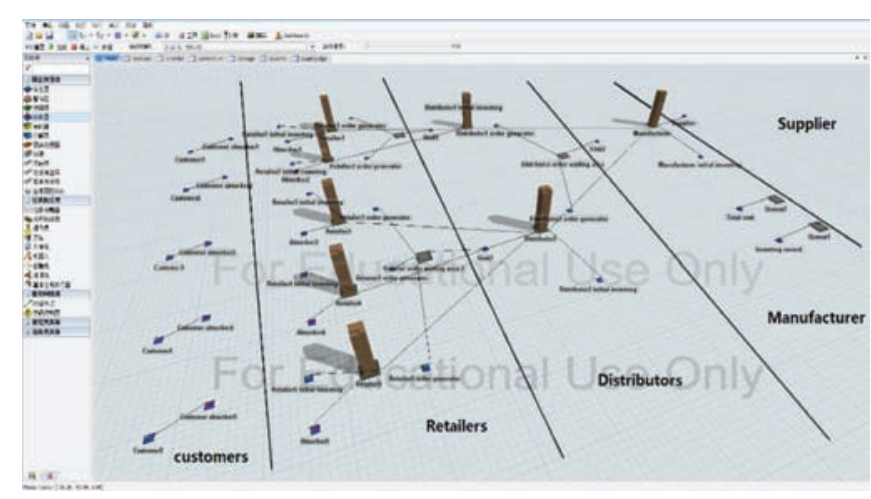

Figure 4 Layout of the simulation model

4.2.2 Logic flow and parameters setting of simulation model

1) Logic flow setting of simulation model

The logic flow of the simulation model is coded in the editor of each entity. The following two graphs show the basic simulation logic flow of the simulation model. The simulation logic flow of the customer side (i.e. retailers-customers) is shown in Figure 5, the simulation logic flow of the supply side (i.e. distributors- retailers, 
manufacturers-distributors and supplier- manufacturer) is shown in Figure 6.

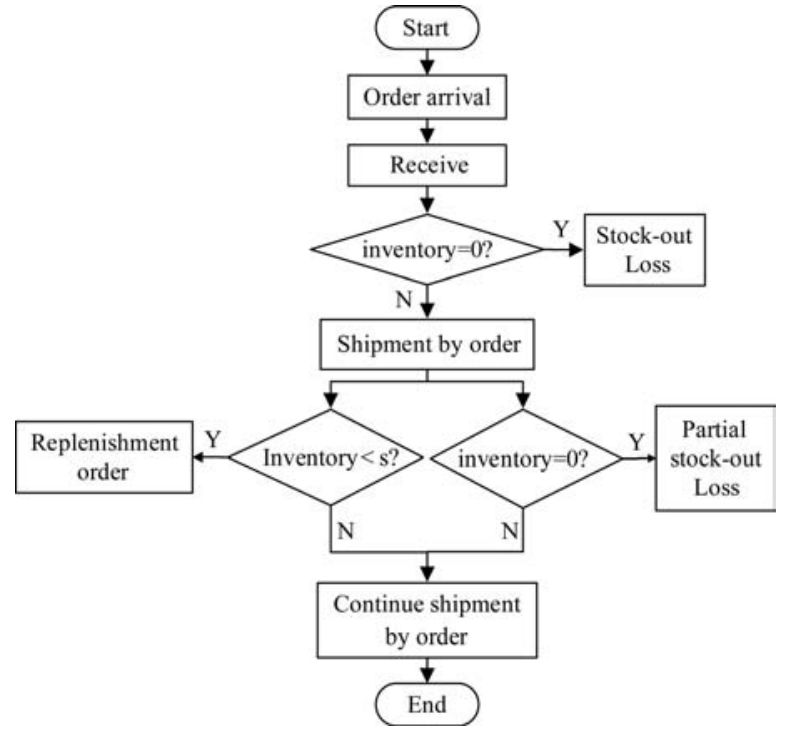

Figure 5 Simulation logic flow of the customer side

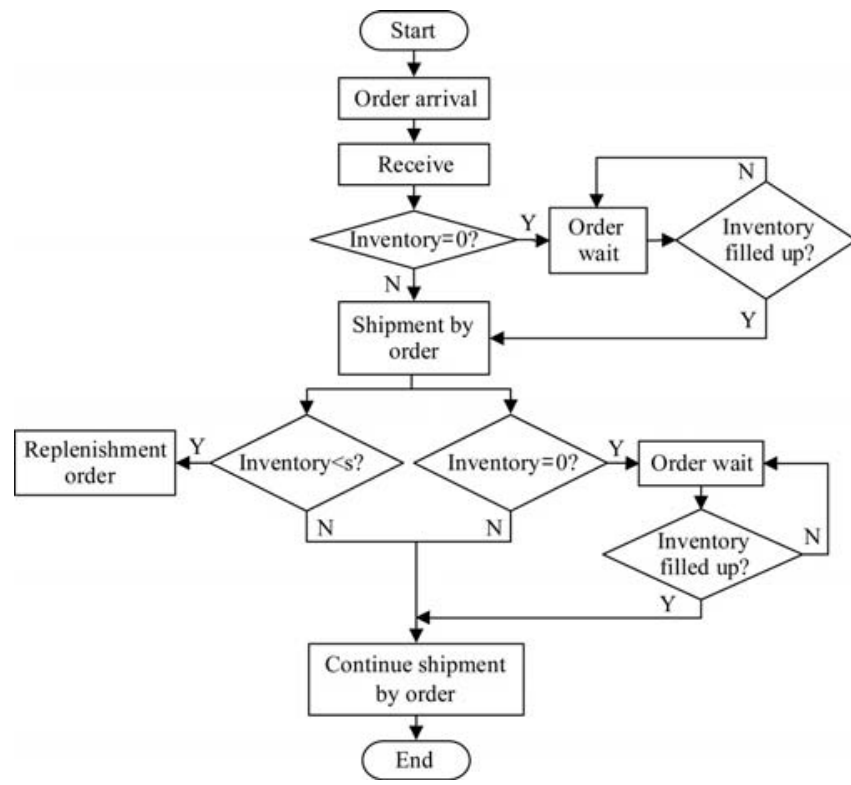

Figure 6 Simulation logic flow of the supply side

2) Simulation parameters setting

The running time of the model is set to 4500 seconds, 30 seconds as one day, The and simulation period as five months (150 days). The simulation parameters are mainly set in the code editor and the parameter settings drop-down menu of each entity. The service level $f$ of inventory system is obtained by the difference between the total order quantity $\left(\mathrm{O}_{2}\right)$ and the total order quantity of shortage $\left(O_{1}\right)$ divided by the total order quantity (Equation (24)).

$$
f=\left(O_{2}-O_{1}\right) / O_{2}
$$

3) Particle swarm optimization algorithm parameters setting

The number of particles in the particle swarm is set as 20 , the number of iterations is 100 , the learning factor $z_{1}=z_{2}=2.05$, the inertia weight adjustment parameter $z_{3}=10, w_{\text {start }}=0.95, w_{\text {end }}=0.4$. Each particle contains 16 variables including order point $(r)$ and order quantity $(Q)$ of 5 retailers, 2 distributors and manufacturers. 4.2.3 Effect of velocity constraint parameter of particle swarm optimization algorithm on the model optimization

In general, in order to prevent the particle velocity of the particle swarm speed too fast which will lead to the particle to fly off the search space, the particle's velocity will be constrained in the $\left(-v_{\max },+v_{\max }\right)$ Larger $v_{\max }$ will fly away from the optimal solution, the smaller $v_{\max }$ will fall into the local search ${ }^{[34]}$, if the search space is $\left(-x_{\max },+x_{\max }\right)$, generally $v_{\max }=k x_{\max }, 0.1 \leq k \leq 1{ }^{[35]}$. In order to explore the effect of $k$ value on the simulation and optimization of discrete system simulation model established in Flexsim environment, the $k$ is set as $1,1 / 2$, and $1 / 5$ to conduct experiments. The other parameters of the particle swarm optimization algorithm are unchanged, and each $k$ scheme runs 6 times. Results are shown in Table 4.

Table 4 Simulation optimization experimental results under different $k$ values

\begin{tabular}{cccccccc}
\hline$K$ & 1 st & 2nd & 3rd & 4th & 5th & 6th & mean value \\
\hline 1 & 70224 & 70666 & 70567 & 70664 & 72242 & 71553 & 70986 \\
$1 / 2$ & 70730 & 71771 & 70490 & 71316 & 70924 & 70779 & 71001.6 \\
$1 / 5$ & 70475 & 71516 & 71531 & 71272 & 71353 & 71236 & 71230.5 \\
\hline
\end{tabular}

In Table 4, by comparing the optimization results and the corresponding mean value of each scheme, the optimization result is better when the $k$ value is bigger. So, in this paper set the $\mathrm{k}$ value as 1 .

\subsection{Simulation results and analysis}

\subsubsection{Simulation results}

Running the simulation-based optimization model to output the inventory cost optimization results after 100 iterations of simulation and optimization. The simulation and optimization curve of total inventory cost is shown in Figure 7. The inventory cost of the initial iterative optimization is 76608 , and the final optimal value is 70224 . The inventory policy of initial iteration and final optimization are shown in Table 5.

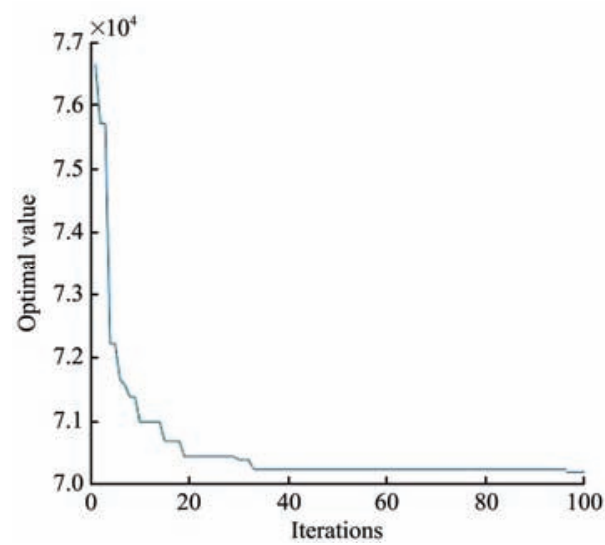

Figure 7 Simulation and optimization curve of total inventory cost

Table 5 Inventory policy of initial iteration and final optimization

\begin{tabular}{ccccccccc}
\hline & $\left(r_{1}^{r}, Q_{1}^{r}\right)$ & $\left(r_{2}^{r}, Q_{2}^{r}\right)$ & $\left(r_{3}^{r}, Q_{3}^{r}\right)$ & $\left(r_{4}^{r}, Q_{4}^{r}\right)$ & $\left(r_{5}^{r}, Q_{5}^{r}\right)$ & $\left(r_{1}^{d}, Q_{1}^{d}\right)$ & $\left(r_{2}^{d}, Q_{2}^{d}\right)$ & $\left(r^{p}, Q^{p}\right)$ \\
\hline Initial & $(83,211)$ & $(54,157)$ & $(119,242)$ & $(102,319)$ & $(42,314)$ & $(229,894)$ & $(300,1072)$ & $(1536,3729)$ \\
Final & $(68,304)$ & $(92,218)$ & $(93,178)$ & $(79,336)$ & $(71,176)$ & $(209,708)$ & $(249,955)$ & $(800,2400)$ \\
\hline
\end{tabular}

4.3.2 Simulation result analysis

Comparing the initial iterative strategy and the final optimization strategy, the simulation results are analyzed. The Content vs. Time (Figure 8) and the Average Content (Figure 9) of 
the initial policy and the final optimization policy of each node were recorded when the model was running. The total orders of each node are shown in Table 6. The quantity of goods loss and
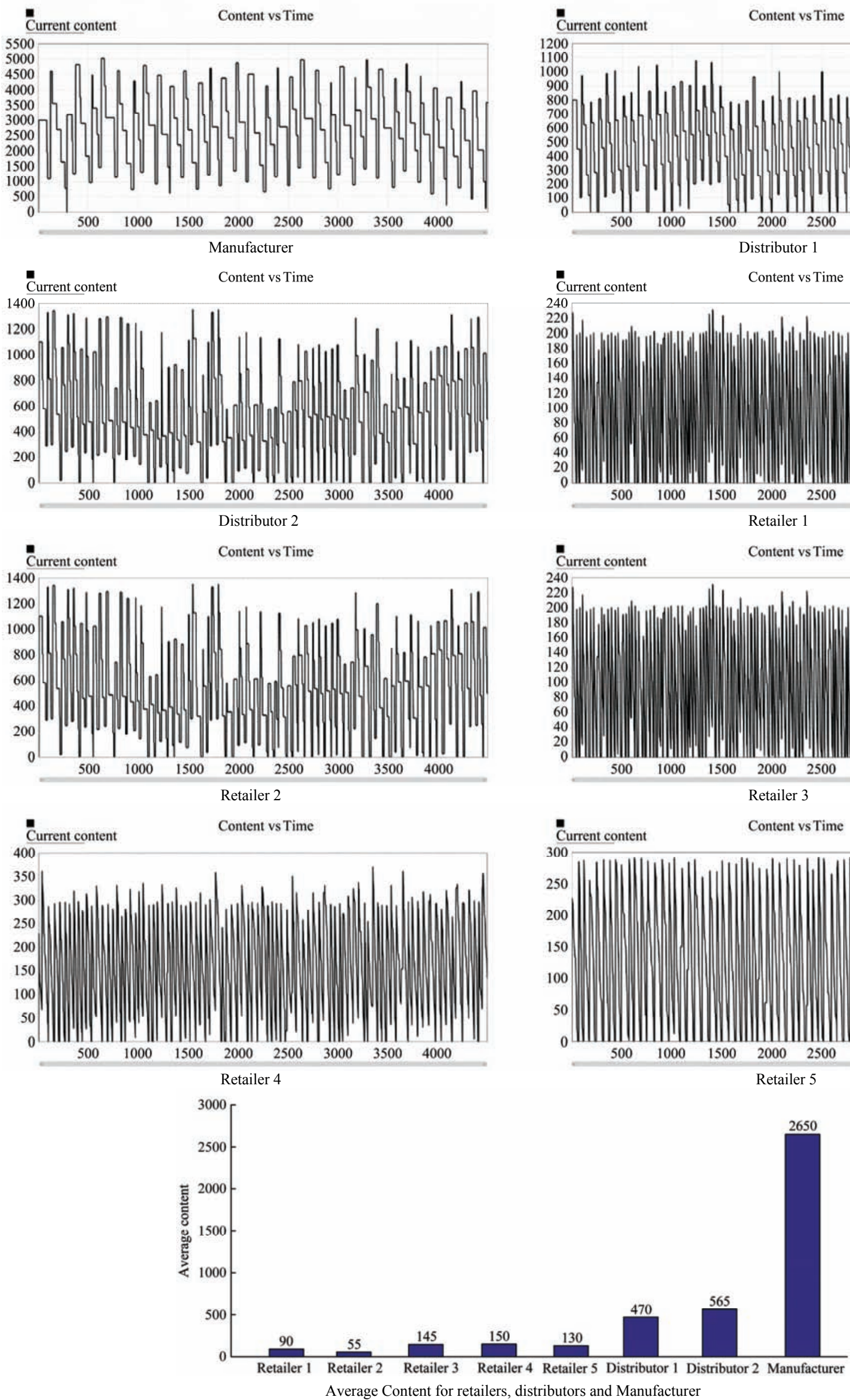

Figure 8 Content vs time and average content of each node in the initial policy policy are shown in Table 7 and Table 8 .

shortage of each node in the initial policy and final optimization
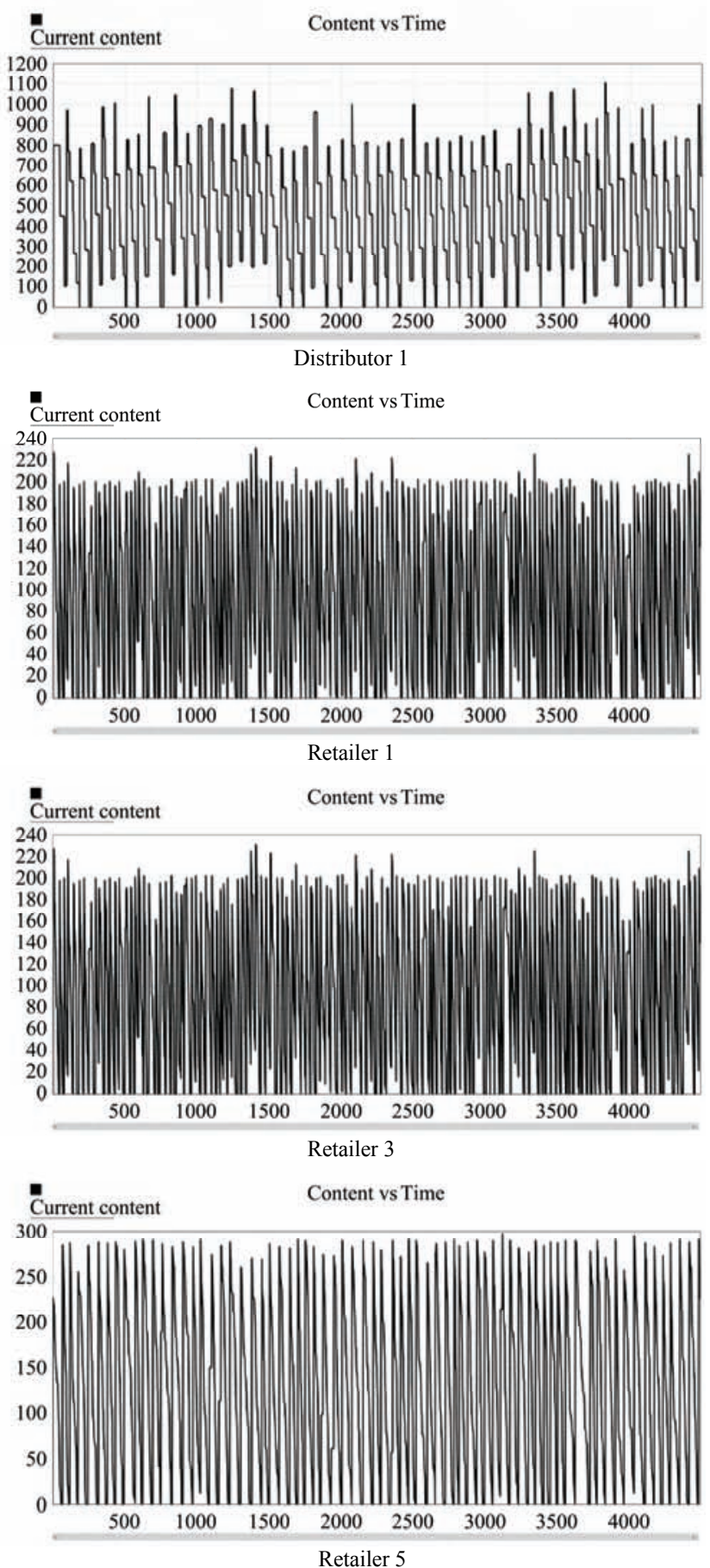

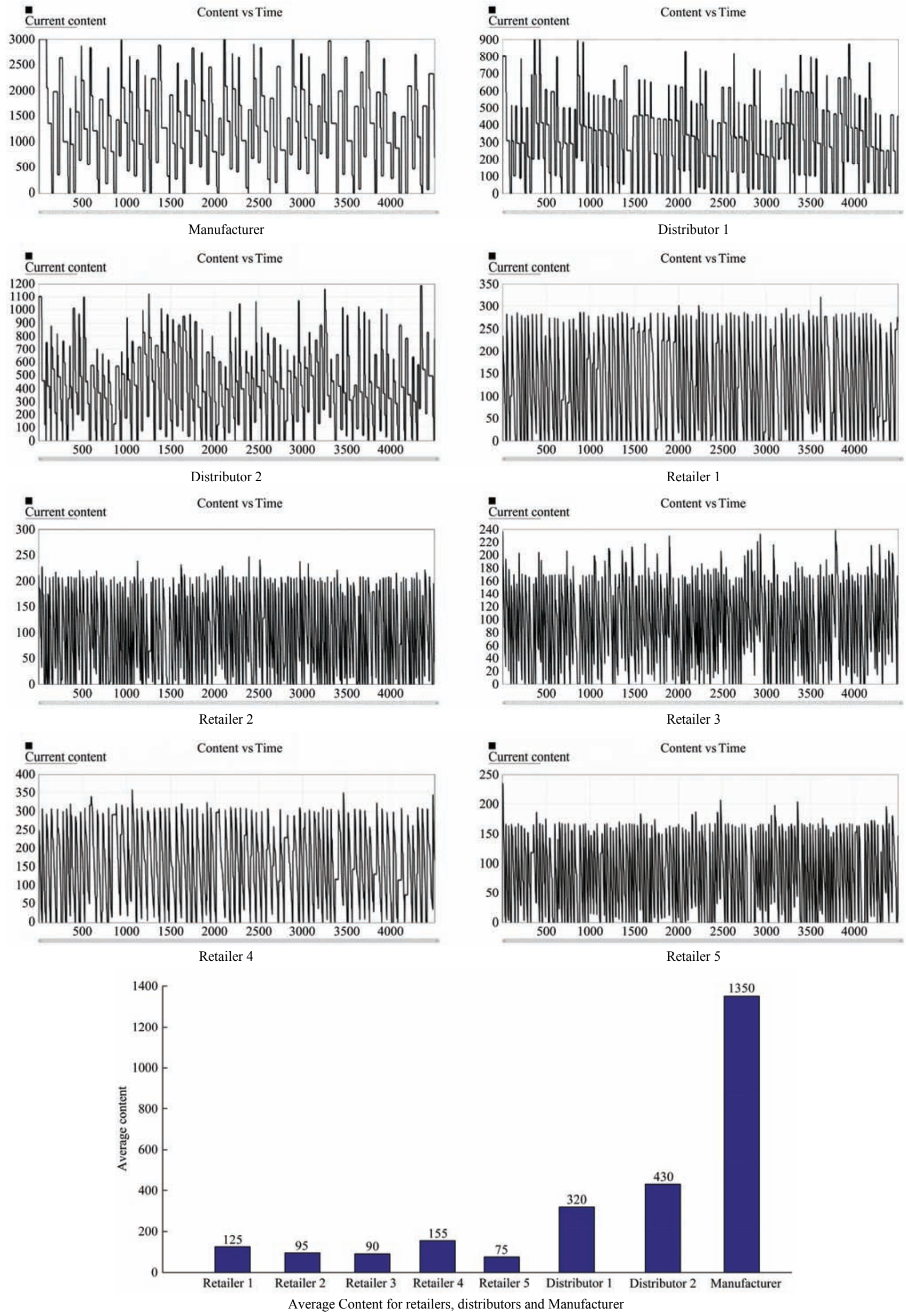

Figure 9 Content vs. time and average content of each node in the final optimization policy 
Table 6 Total orders in each node of the initial policy and final optimization policy

\begin{tabular}{|c|c|c|c|c|c|c|c|c|}
\hline & Retailer 1 & Retailer 2 & Retailer 3 & Retailer 4 & Retailer 5 & Distributor 1 & Distributor 1 & Manufacturer \\
\hline Initial & 133 & 147 & 109 & 90 & 72 & 56 & 68 & 35 \\
\hline \multirow[t]{2}{*}{ Final } & 86 & 130 & 129 & 74 & 124 & 74 & 70 & 51 \\
\hline & Retailer1 & Retailer2 & Retailer3 & Retailer4 & Retailer5 & Distributor1 & Distributor1 & Manufacturer \\
\hline Initial & 1314 & 1098 & 2110 & 2128 & 1696 & 963 & 1540 & 7703 \\
\hline Final & 1710 & 1292 & 1090 & 1915 & 1048 & 1067 & 1309 & 7224 \\
\hline
\end{tabular}

Table 8 Quantity of shortage of the initial policy and final optimization policy

\begin{tabular}{cccccc}
\hline & Retailer 1 & Retailer 2 & Retailer 3 & Retailer 4 & Retailer 5 \\
\hline Initial & 6861 & 12363 & 1413 & 3000 & 4441 \\
Final & 10079 & 6693 & 2572 & 5020 & 4575 \\
\hline
\end{tabular}

According to the Content vs. Time chart and Average Content chart, and comparing initial policy with optimization policy, the results show that the inventory of Retailer 1 and Retailer 2 in optimization policy are larger than initial policy's, for other nodes, the optimization policies are less than initial policy's. The results also show that, the smaller the value of $r$ and $Q$ is, the more conducive to reduce the inventory. But $r$ and $Q$ value cannot be infinitely small, if the $r$ and $Q$ value are too small, the shortage will increase, resulting in an increase in the shortage cost shown in Table 8 .

From Table 6, the optimization policy has more orders than the initial policy, order cost of optimization policy is slightly bigger than the initial policy's. Comparing the $r$ value, $Q$ value and the total orders of each node, we know that the smaller the difference between $r$ and $Q$, the more frequent are the orders. From Table 6 and Table 5, the optimization strategy reduces the inventory significantly by reducing the $r$ and $Q$ value, but it also increases the number of orders, which leads to the increase of the order cost.

The transportation cost of the inventory system depends on the order number and the quantity of order, although the order number of the initial policy is less than the optimization policy's, the total order quantity of the initial policy is larger than it of the optimization policy. Table 5 and Table 6 show that, the transportation cost of initial policy is slightly larger than optimization policy's.

The quantity of goods loss is related to the inventory and storage time: the goods turnover time increases with $s$ and $Q$ value increase, at the same time the quantity of goods loss increases. From Table 5, the $r$ and $Q$ value of each node in the optimization policy are not always less than the initial policy's. But in general, the $r$ and $Q$ value of optimization policy are less than the initial policy's, so the goods loss quantity of optimization policy is less than the initial policy's (as shown in Table 7).

From Table 8, the shortage quantity of initial policy is slightly less than the optimization policy's. According to Table 1 and Table 8, the quantity of shortage is mainly related to the $r$ value and the customer's demand: it is more easily to lead to shortage when the $r$ value reduces, and the customer demand increases. In some experimental results, the $r$ value is sometimes very small in a retailer, which leads to more shortage in the node, and the service level is very low. Therefore, the algorithm will lead to the increase of the shortage of a node and make the overall policy optimal.

From the above analysis, the control policy of multi-echelon inventory is a complex problem which is restricted by many factors. Reducing the $r$ and $Q$ values will reduce inventory but will result in an increase in the shortage cost. Increasing the $r$ value will reduce the shortage cost but increase the inventory cost and goods loss cost. At the same time if the $Q$ value is too small, it will increase the order cost and transportation cost; if the $Q$ value is too big, the goods loss cost will increase. So it's not better when the entire cost index is small in the multi-echelon inventory system, but various factors restrict each other to achieve balance, which will make the inventory cost lowest and achieve the optimal inventory policy.

4.3.3 Comparative analysis of simulation policy and mathematical policy

The particle swarm optimization algorithm is used to solve the mathematical model, same with the simulation model, $T_{t}=150$ days First, to solve the retailer's order quantity $Q_{i}^{r}$, order point $r_{i}^{r}$. Then find the distributor and the manufacturer's order quantity and order point, and finally get the optimal inventory cost. The optimal cost of inventory system is 73757 . The optimization policy, the number of orders, the amount of goods loss compared with simulation optimization method and mathematical method are shown in Tables 9-11. The average inventory of each node in the mathematical policy is shown in Table 12 .

Table 9 Simulation optimization policy and mathematical optimization policy

\begin{tabular}{ccccccccc}
\hline & $\left(r_{1}^{r}, Q_{1}^{r}\right)$ & $\left(r_{2}^{r}, Q_{2}^{r}\right)$ & $\left(r_{3}^{r}, Q_{3}^{r}\right)$ & $\left(r_{4}^{r}, Q_{4}^{r}\right)$ & $\left(r_{5}^{r}, Q_{5}^{r}\right)$ & $\left(r_{1}^{d}, Q_{1}^{d}\right)$ & $\left(r_{2}^{d}, Q_{2}^{d}\right)$ & $\left(r^{p}, Q^{p}\right)$ \\
\hline simulation & $(68,304)$ & $(92,218)$ & $(93,178)$ & $(79,336)$ & $(71,176)$ & $(209,708)$ & $(249,955)$ & $(800,2400)$ \\
mathematical & $(131,300)$ & $(131,300)$ & $(94,255)$ & $(113,278)$ & $(94,255)$ & $(326,1029)$ & $(254,908)$ & $(795,1428)$ \\
\hline
\end{tabular}

Table 10 Total orders in each node of Simulation and mathematical optimization policy

\begin{tabular}{ccccccccc}
\hline & Retailer 1 & Retailer 2 & Retailer 3 & Retailer 4 & Retailer 5 & Distributor 1 & Distributor 1 & Manufacturer \\
\hline simulation & 86 & 130 & 129 & 74 & 124 & 74 & 70 \\
mathematical & 125 & 125 & 107 & 116 & 107 & 75 & 66 & 101 \\
\hline
\end{tabular}

Table 11 Quantity of goods loss of simulation and mathematical optimization policy

\begin{tabular}{ccccccccc}
\hline & Retailer 1 & Retailer 2 & Retailer 3 & Retailer 4 & Retailer 5 & Distributor 1 & Distributor 1 & Manufacturer \\
\hline simulation & 1710 & 1292 & 1090 & 1915 & 1048 & 1067 & 1309 \\
mathematical & 2849 & 2849 & 2410 & 2641 & 2410 & 1913 & 1687 \\
\hline
\end{tabular}


Table 12 Average inventory of each node in the mathematical policy

\begin{tabular}{ccccccccrr}
\hline & Retailer 1 & Retailer 2 & Retailer 3 & Retailer 4 & Retailer 5 & Distributor 1 & Distributor 1 & Manufacturer \\
\hline Inventory & 146 & 146 & 124 & 136 & 124 & 510 & 750 & 702 & 450 \\
\hline
\end{tabular}

As shown in Table 9, at the distributors and retailers node, in addition to $Q_{2}^{d}$, the order point $r$ and order quantity $Q$ of mathematical methods are bigger than the simulation method, So the average inventory and goods loss of mathematical policy at retailers and distributors node are bigger than that of simulation policy (Tables 11, 12, and Figure 9), thus the storage cost and goods loss cost of mathematics policy at retailers and distributors node are bigger than simulation policy. At the same time, it can be seen that the total difference of the $Q$ and $r$ values of the mathematical strategy is larger, thus the total number of orders at the retailer and distributor nodes is more (Table 10), and the total order quantity is larger. Therefore, transportation cost and ordering cost are also bigger than simulation policy.

The order point $r$ and order quantity $Q$ of the mathematical policy is smaller than the simulation policy at the node of manufacturer (Table 9), compared to mathematical policy the inventory cost and damage cost of simulation policy will be higher at the node of manufacturer (see Table 12, Figures 8 and 10). The $Q$ value of simulation policy is higher than mathematical policy at the node of manufacturer, because it set up the shortage cost in the simulation policy, higher $Q$ value can better meet the downstream demand, thereby reducing the Shortage cost of system. At the same time, because of the $Q$ value is smaller, so the difference between the $r$ value and the $Q$ value of mathematical policy is smaller, thus the number of orders of mathematical policy is far more than the simulation policy (Table 10), so the order cost of mathematical policy is bigger than the simulation method at the node of manufacturer.

And the inventory cost obtained by mathematical model (73757) is bigger than simulation model (70224), it can be seen that the simulation-based optimization method has more advantages to solve complex system problems than mathematical method.

\section{Conclusions}

In this study, the multi-echelon inventory control policy for fresh agricultural products was investigated. We propose the simulation-based optimization model with the Flexsim simulation software and improved particle swarm optimization algorithm. Firstly, the inventory cost of a three-level fresh agricultural products inventory system was mathematically analyzed. Then, the simulation-based optimization model of the multi-echelon inventory system for fresh agricultural products was proposed by using the Flexsim simulation software and the improved particle swarm optimization algorithm. Finally, the multi-echelon inventory system was simulated based on a large number of survey data. Simulation results the inventory cost (70224) obtained by simulation method is better than the mathematical method (73757), which shows that the simulation optimization method is more advantageous to solve complex system problems. However, there are some shortcomings in the proposed simulation-based optimization model: First, the iterative running time of the simulation optimization model is too long. Second, when the inventory system achieves the overall optimum, the service level of a node may reduce, failing to reach individual optimal. Third, we have not considered the effect of the price and the freshness of the goods on demand.

\section{Acknowledgements}

We acknowledge that this work was supported by the science and technology innovation fund of Henan Agricultural University, No.KJCX2016A04, Henan province institution of higher learning youth backbone teachers training program, No.2016GGJS-036, and Henan Provincial Department of Science and Technology Research Project under Grant 192102110205.

\section{[References]}

[1] Mo J T, Chen G M, Fan T, Mao H. Optimal ordering policies for perishable multi-item under stock-dependent demand and two-level trade credit. Applied Mathematical Modelling, 2014; 38(9-10): 2522-2532.

[2] Qiu Y Z, Qiao J, Pardalos P M. Optimal production, replenishment, delivery, routing and inventory management policies for products with perishable inventory. Omega-International Journal of Management Science, 2019; 82: 193-204.

[3] Savadkoohi, E, Mousazadeh M, Torabi S A. A possibilistic location-inventory model for multi-period perishable pharmaceutical supply chain network design. Chemical Engineering Research \& Design, 2018; 138: 490-505.

[4] Janssen L, Diabat A, Sauer J. A stochastic micro-periodic age-based inventory replenishment policy for perishable goods. Transportation Research Part E-Logistics and Transportation Review, 2018; 118: 445-465.

[5] Liu H Y, Zhang J L, Zhou C. Optimal purchase and inventory retrieval policies for perishable seasonal agricultural products. Omega-International Journal of Management Science, 2018; 79: 133-145.

[6] Kaya O, Ghahroodi S R. Inventory control and pricing for perishable products under age and price dependent stochastic demand. Mathematical Methods of Operations Research, 2018; 88(1): 1-35.

[7] Köchel P, Nieländer U. Simulation-based optimisation of multi-echelon inventory systems. International Journal of Production Economics, 2005; 93-94: 505-513.

[8] Jiang C H, Hu Y H. Simulation and optimization of Stochastic (s, S) Inventory System Based on Genetic Algorithm. Journal of East China Normal University: Natural Science, 2006; 3: 71-76. (in Chinese)

[9] Carson Y, Maria A. Simulation optimization: methods and application. Proceedings of 1997 Winter Simulation Conference, 1997: pp.118-126.

[10] Salimi S, Mawlana M, Hammad A. Performance analysis of simulation-based optimization of construction projects using high performance computing. Automation in Construction, 2018; 87: $158-172$.

[11] Delgarm N, Sajadi B, Delgarm S. A novel approach for the simulation-based optimization of the buildings energy consumption using NSGA-II: Case study in Iran. Energy and Buildings, 2016; 127: 552-560.

[12] Shamshiri R R, Hameed I A, Pitonakova L, Weltzien C, Balasundram S K, Yule I J, et al. Simulation software and virtual environments for acceleration of agricultural robotics: Features highlights and performance comparison. Int J Agric \& Biol Eng, 2018; 11(4): 15-31.

[13] Heidary M H, Aghaie A, Jalalimanesh A. A simulation-optimization approach for a multi-period, multi-objective supply chain with demand uncertainty and an option contract. Transactions of the Society for Modeling and Simulation International, 2018; 94(7): 649-662.

[14] Zhao W D, Wang D W. Simulation-based optimization on control strategies of three-echelon inventory in hybrid supply chain with order uncertainty. IEEE Access, 2018; 6: 54215-54223.

[15] Avci M G, Selim H. A multi-objective simulation-based optimization approach for inventory replenishment problem with premium freights in convergent supply chains. Omega-International Journal of Management Science, 2018; 80: 153-165.

[16] Güller M, Uygun Y, Noche B. Simulation-based optimization for a capacitated multi-echelon production-inventory system. Journal of Simulation, 2015; 9(4): 325-336.

[17] He J, Huang Y, Chang D. Simulation-based heuristic method for container supply chain network optimization. Advanced Engineering Informatics, 2015; 29(3): 339-354.

[18] Thammatadatrakul P, Chiadamrong N. Optimal inventory control policy 
of a hybrid manufacturing - remanufacturing system using a hybrid simulation optimisation algorithm. JOURNAL OF SIMULATION, 2019; 13(1): 14-27.

[19] Saif A, Elhedhli S. Cold supply chain design with environmental considerations: A simulation-optimization approach. European Journal of Operational Research, 2016; 251(1): 274-287.

[20] Attar A, Raissi S, Khalili-Damghani K .Simulation-optimization approach for a continuous-review, base-stock inventory model with general compound demands, random lead times, and lost sales. Transactions of the Society for Modeling and Simulation International, 2016; 92(6): 547-564.

[21] Rowshon M K, Iqbal M, Mojid M A, Amin M S M, Lai S H. Optimization of equitable irrigation water delivery for a large-scale rice irrigation scheme. Int J Agric \& Biol Eng, 2018; 11(5): 160-166.

[22] Attar A, Raissi S, Khalili-Damghani K. A simulation-based optimization approach for free distributed repairable multi-state availability-redundancy allocation problems. Reliability Engineering \& System Safety, 2017; 157: 177-191.

[23] Jia H L, Chen Y L, Zhao J L, Guo M Z, Huang D Y, Zhuang J. Design and key parameter optimization of an agitated soybean seed metering device with horizontal seed filling. Int J Agric \& Biol Eng, 2018; 11(2): 76-87.

[24] Nedělková Z, Lindroth P, Patriksson M. Efficient solution of many instances of a simulation-based optimization problem utilizing a partition of the decision space. Annals of Operations Research, 2018; 265(1): 93-118.

[25] Cui L F, Mao H P, Xue X Y, Ding S M, Qiao B Y. Optimized design and test for a pendulum suspension of the crop spray boom in dynamic conditions based on a six DOF motion simulator. Int J Agric \& Biol Eng, 2018; 11(3): 76-85.
[26] Bardzinski P J; Walker P, Krol R. Simulation of random tagged ore fow through the bunker in a belt convering system. International Journal of Simulation Modelling, 2018; 17(4): 597-608.

[27] Jiao Y L, Xing X C, Zhang P. Multi-objective storage location allocation optimization and simulation analysis of automated warehouse based on multi-population genetic algorithm. Concurrent Engineering-Research and Applications, 2018; 26: 367-377.

[28] Grzybowska K, Kovacs G. The modelling and design process of coordination mechanisms in the supply chain. Journal of Applied Logic, 2017; 24: 25-38

[29] Kierzkowski A, Kisiel, T. Simulation model of security control system functioning: A case study of the Wroclaw Airport terminal. Journal of Air Transport Management, 2017; 64: 173-185.

[30] Flexsim 3D Simulation Software User Manual (Version Flexsim 7.3.0), 2014. Flexsim Software Products Inc.

[31] Chen Y N, Xie B, Du Y F, Mao E R. Powertrain parameter matching and optimal design of dual-motor driven electric tractor. Int J Agric \& Biol Eng, 2019; 12(1): 33-41

[32] Chen G M, Jia J Y, Han Q. Study on the Strategy of Decreasing Inertia Weight in Particle Swarm Optimization Algorithm. Journal of Xi'an Jiaotong University, 2006; 40(1): 53-56, 61. (in Chinese)

[33] Clerc M. The swarm and the queen: towards a deterministic and adaptive particle swarm optimization. Piscataway, NJ: IEEE Service Center, 1999; 1951-1957.

[34] Eberhart R C, Shi Y. Particle swarm optimization: development, applications and resources. Proceedings of the IEEE Congress on Evolutionary Compution. Piscatawy, NJ: IEEE Service center, 2001; pp.81-86.

[35] Yang W, Li Q Q. Survey of panicle swarm optimization algorithm. Engineering Science, 2004; 6(5): 87-94. (in Chinese) 